\title{
La subcontratación de la obra de arte y sus problemas en la investigación histórico-artística: el caso de León Picardo
}

The subcontracting of art work and its problems in the art-historical research: the case of León Picardo

\section{Eloy González Martínez ${ }^{1}$}

Licenciado en Historia del Arte

Master en Arte Español de Época Moderna, UCM

\begin{abstract}
Resumen: La subcontratación, o incluso el traspaso de contratos por parte de los pintores, ha sido una práctica habitual dentro de la génesis de retablos. La presente investigación, centrada en el caso concreto de León Picardo, pretende reflejar los problemas histórico-artísticos que este tipo de organización puede acarrear, ya que puede llevar a equívocos a la hora interpretar el documento escrito que sirve como base para establecer el estilo de un pintor. Nos obliga por tanto a tratar la información documental con cautela, ya que hay distintas variables a tener en cuenta para darle validez, y a cuestionar su virtualidad informativa en virtud del contexto laboral en el que se mueven los artistas
\end{abstract}

Palabras clave: Subcontratación de obras de arte; Siglo XVI; León Picardo; Retablo de San Lesmes; Burgos; Alonso Gallego; Pintura-Investigación

\begin{abstract}
Subcontracting, or even the transfer of contracts by painters, has been a common practice in the genesis of altarpieces. This research, focused on the case of Leon Picardo, is intended to reflect the historical and artistic problems of the organization of the artistic workshops through the documents that we have about them. The written sources can be misleading when they serve as a basis for the style of a painter. It forces us therefore to treat the documents and its information with caution
\end{abstract}

Key-words: Outsourcing of art work; 16th century; San Lesmes altarpiece; Burgos; Leon Picardo; Alonso Gallego; Painting- Research

\footnotetext{
${ }^{1}$ https://orcid.org/0000-0003-0311-3708
}

(C) 2017 Philostrato. Revista de Historia y Arte 


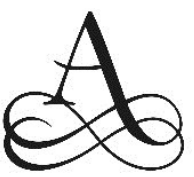

la hora de constituir el catálogo de un pintor, el investigador necesita una obra de base que establezca su estilo de una manera inequívoca. Esta obra fundamental se instituye a través de un trabajo o bien firmado (no habitual en época moderna), o bien documentado por medio de contratos y capitulaciones que se encuentran habitualmente en los archivos de protocolos notariales.

Sin embargo, muchas veces estos contratos se subrogan o se traspasan. Nos encontramos entonces con el fenómeno de la subcontratación o el traspaso en la ejecución de obras de arte por parte de los pintores, que ha sido una práctica habitual dentro de la génesis de retablos ${ }^{2}$, y por el que se crea una controversia historiográfica que procede de las formas de trabajo de los talleres y artistas, que a veces funcionaban como verdaderos empresarios y contratistas, subcontratando, a su vez, la ejecución de las obras concertadas. La idea del "artista empresario" ya ha sido tratada por Joaquín Yarza en la figura del pintor Blasco de Grañén (doc. Zaragoza 1422-1459), y puede explicar la contradicción abierta sobre el verdadero estilo de un pintor foráneo trabajando en España como León Picardo³.

Los datos biográficos sobre el pintor son escasos. Por el nombre, se le supone originario del norte de Francia, lo que explicaría su influencia flamenca. Emile Bertaux suponía que pudo salir de su país para pintar vidrieras, como los pintores de Troyes que trabajaron en Toledo y en Sevilla. Fue vecino de Burgos, en la parroquia de San Gil, por lo menos desde 1509 hasta 1530. Participa en el conflicto de las Comunidades, apoyando a la nobleza sublevada en Burgos. Fray Prudencio de Sandoval (ca. 1560-1620), benedictino, obispo de Tuy, y continuador de las crónicas de reyes españoles de Florián Ocampo y Ambrosio de Morales (1513-1591), en su Historia y Vida del Emperador Carlos $V$, dice que es el Picardo que aparece como interlocutor de las Medidas del Romano de Diego de Sagredo (ca. 1490-1528). Su actividad artística no se circunscribe a la pintura, y se le atribuye también una labor como escultor, siendo importantes sus trabajos de policromía y dorado de retablos, muchas veces en colaboración con Felipe Bigarny (ca. 1475-1542) y Diego de Siloé (ca. 1495-1563). Destaca sobre todo su intervención en la Capilla de los Condestables de la catedral de Burgos, o la policromía del retablo mayor de la catedral de Oviedo (1529), sustituyendo a

\footnotetext{
2 Una revisión de la documentación sobre pintores conservada en el Archivo Histórico de Salamanca nos puede dar una idea de ello. Andrea Barbero García y Teresa de Miguel Diego, Documentos para la historia del arte en la provincia de Salamanca. Siglo XVI, (Salamanca: Ediciones de la Diputación de Salamanca, 1987), pp. 129-139.

3 Joaquín Yarza Luaces, "Posible respuesta a una duda: el maestro desconocido del retablo gótico de Ejea de los Caballeros y el artista empresario", en Tiempo y espacio en el arte. Homenaje al profesor Antonio Bonet Correa, vol. I, (Madrid: Editorial Complutense, 1994), pp. 149-160. También Gloria Fernández Somoza, "El mundo laboral del pintor del siglo XV en Aragón", Locus Amoenus, 3, (1997), pp. 45-49.
} 
Alonso Berruguete (ca. 1490-1561). Finalmente, falleció y fue enterrado en Burgos en $1541^{4}$.

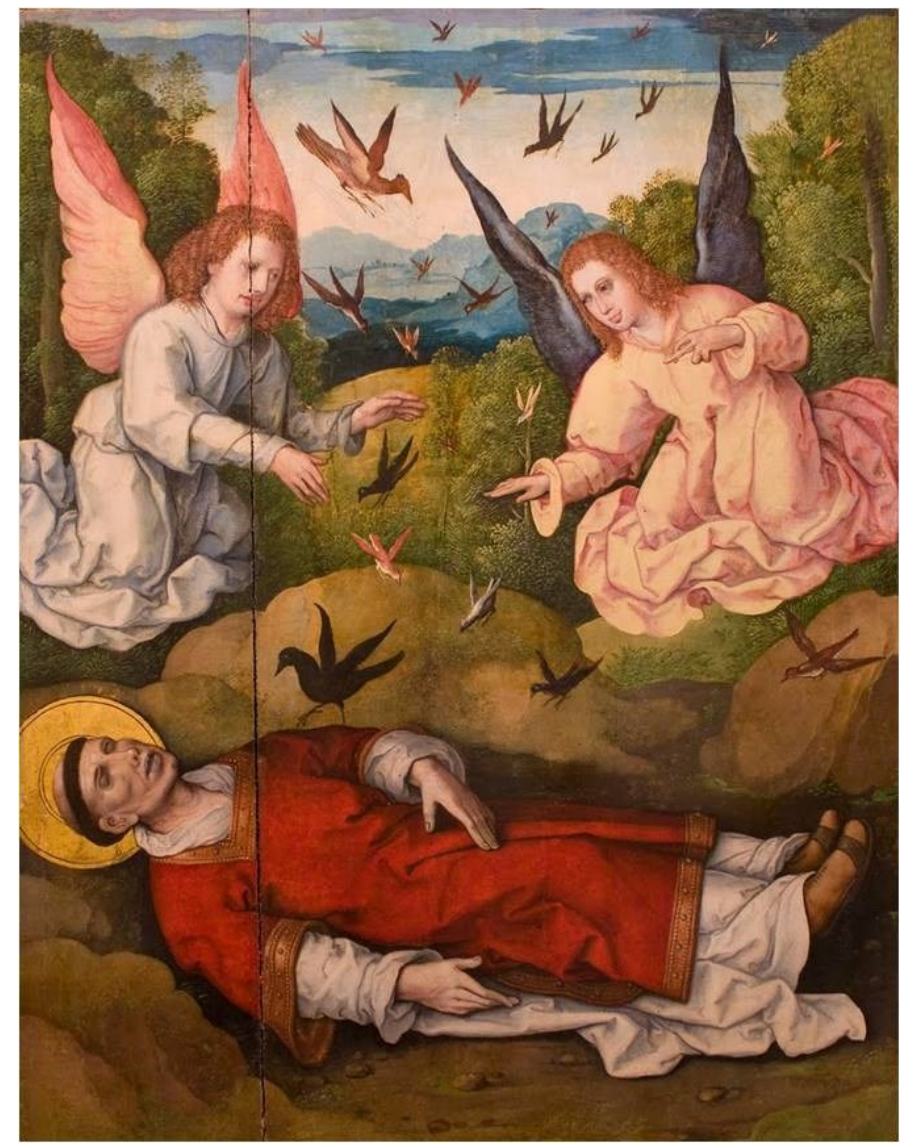

Fig. 1. León Picardo, El cadáver de San Vicente guardado por el cuervo, 1524, Museo de la Catedral de Burgos

A pesar de la escasez de datos biográficos, pensábamos que el pintor francés era una de estas figuras inequívocas en cuanto a la identificación de su obra. Su estilo pictórico tenía como base unas tablas actualmente conservadas en el Museo de la Catedral de Burgos, procedentes de un retablo dedicado a San Vicente, contratado en septiembre de 1524 por Picardo para la iglesia de Santa Casilda 5 . A partir de estas pinturas (fig. 1), serán sobre todo Diego

\footnotetext{
4 Para todos estos datos biográficos, se puede consultar Luciano Huidobro Serna, "Artistas burgaleses. León Picardo pintor y escultor", Boletín de la Comisión de Monumentos Históricos y Artísticos de Burgos, 66, (1939), pp. 189-194; Matías Martínez Burgos, "Datos familiares de León Picardo pintor", Boletín de la Institución Fernán González, 115, 19, (1951), pp. 490-499; María Victoria Sáez Terreros, "Pintura y pintores de la primera mitad del siglo XVI en Santo Domingo de la Calzada", Boletín de la Institución Fernán González, 197, (1981), pp. 387-389. Algún dato escabroso, y que confirma la estrecha relación personal que tenía con Bigarny, lo encontramos en Isabel Fuentes Rebollo, "Felipe Bigarny veedor y examinador de obras de talla", Boletín del Museo Nacional de Escultura, 5, (2001), p. 9.

${ }^{5}$ El santuario de Santa Casilda pertenece al municipio de Salinillas de Bureba, localidad situada a unos 40 kilómetros al noreste de la ciudad de Burgos. La iglesia estaba dedicada a San Vicente, de ahí el tema de las tablas. Con posterioridad, pasó a estar bajo la advocación de Santa Casilda, ya que ahí se conserva su cuerpo. "(...) que el dho leon aya de fazer e faga un retablo para la capilla mayor de la dha yglia de san bicente con la historia de sant bicente de madera y pintura en la que ha de llevar honze pies y $\mathrm{m}^{\circ} \mathrm{de}^{\mathrm{a}}$ alto y diez de ancho como está traçado en la muestra enque ha de aver una imagen de sant bicente de bulto y dos ystorias a los lados del bulto de pincel de la historia de sant bicente". Pilar Silva Maroto, "La pintura española sobre tabla de los siglos XV y XVI, en la Catedral de Burgos", en Las pinturas sobre tabla de los siglos XV y XVI en la Catedral de Burgos, (Burgos: Cabildo Metropolitano y Asociación de Amigos de la Catedral, 1994), p 175.
} 
Angulo y Chandler Rathfon Post quienes aumenten el catálogo de Picardo ${ }^{6}$. En sus estudios, Diego Angulo define su estilo dentro de las influencias de los pintores flamencos rafaelistas (Gossaert y Van Orley), así como ecos compositivos de Quentin Metsys.
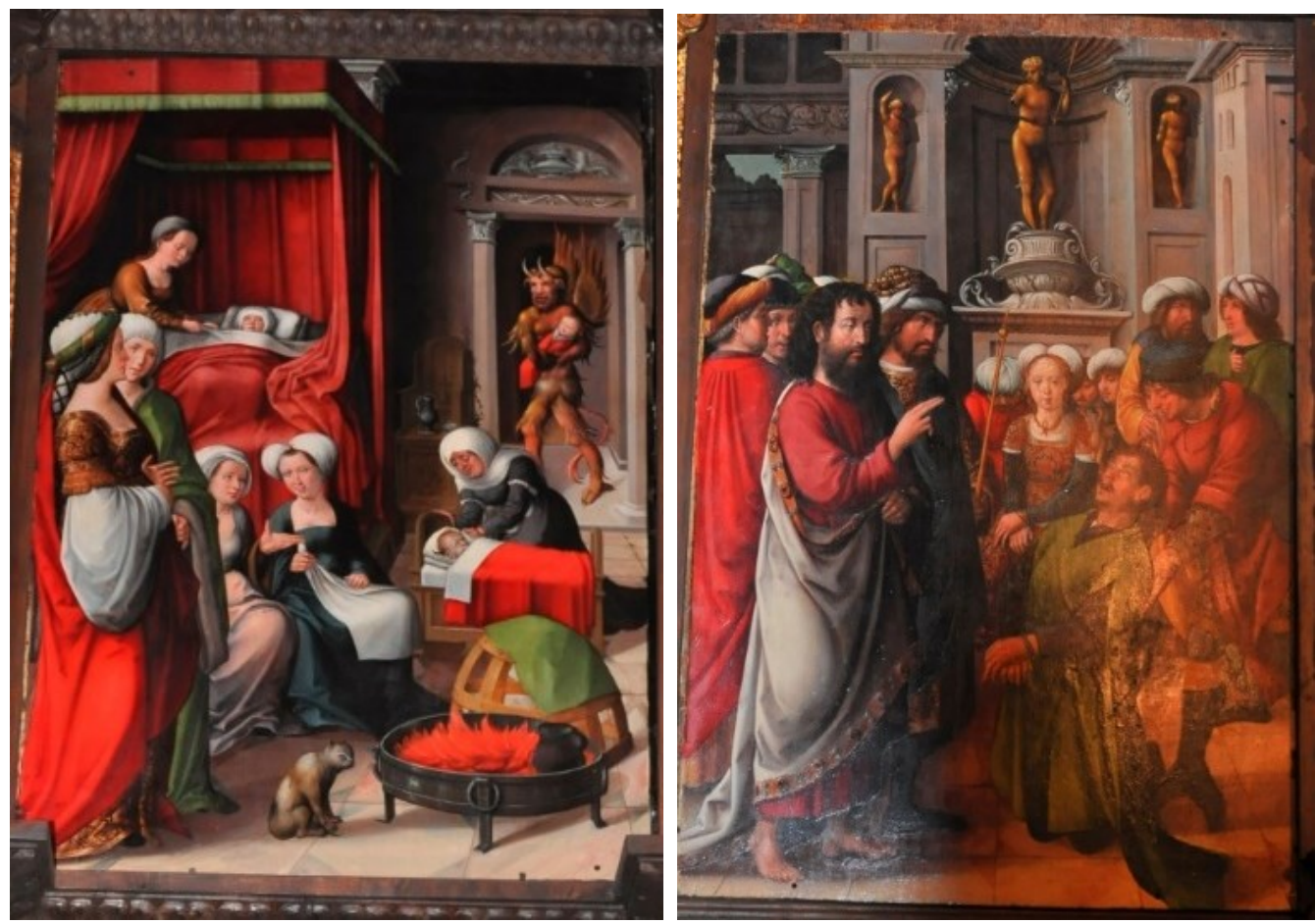

Fig. 2. Alonso Gallego (atrib), El rapto de San Bartolomé y San Bartolomé en el templo de Astaroth , 1515, Retablo de San Bartolomé, Iglesia de San Lesmes, Burgos (ㄷ foto autor)

Sin embargo, esta seguridad en el conocimiento de su estilo se ve cuestionada en 1996, tras la publicación de un artículo de Damián Luengo y Pilar Silva7. Ambos autores sostendrán que el estilo del pintor francés habría que asociarlo con el de cuatro tablas con la historia de San Bartolomé que se conservan en un retablo de la iglesia de San Lesmes de Burgos, identificándolo con el contratado por León Picardo y Felipe Bigarny con Francisco Gumiel en 1515 para la iglesia de San Esteban de Burgos (fig. 2 y $3)^{8}$.

\footnotetext{
6 Diego Angulo Iñiguez, "León Picardo", Archivo Español de Arte, 68, (1945), pp. 84-96. También Ars Hispaniae, v. XII, Pintura del Renacimiento, (Madrid: ed. Plus-Ultra, 1954), pp.110-111. Asimismo, del mismo autor, "El retablo de Santa Catalina de León Picardo, en Barbarín", Príncipe de Viana, 94 y 95, (1964), pp. 49 y 50; Chandler Rathfon Post, A History of Spanish Painting, tomo IX, (Cambridge: Harvard University Press, 1947), pp. 633-636.

7 Damián Luengo Pedrera y Pilar Silva Maroto, "Identificación del verdadero estilo de León Picardo", Archivo Español de Arte, 273, 99, (1996), pp. 23-43.

8 "(...) yo el dicho Leon picardo haga de pintura el retablo que el dicho maestre filipe [Bigarny] ha de hacer de tabla de la muestra que está firmada de mi el dicho escribano en que ha de aver quatro estorias de pincel de la estoria del señor San Bartolomé e todo lo otro estofado e dorado testigos leon picardo pintor e Bernardino de Valmaseda su criado". El contrato había sido publicado por Teófilo López Mata en 1946. Teófilo López Mata, El barrio y la iglesia de San Esteban de Burgos, (Burgos: Publicaciones del Excelentísimo Ayuntamiento de Burgos, 1946), pp. 106-108. La obra se consideraba perdida hasta el
} 
La visita de Damián Luengo a la iglesia de San Lesmes de Burgos supone el origen de la investigación sobre el retablo conservado en esta iglesia ${ }^{9}$. El per fecto encaje de las tablas en el retablo y la coherencia de cronología de las mismas con los relieves que lo decoran le hacen pensar que, aunque se ha-
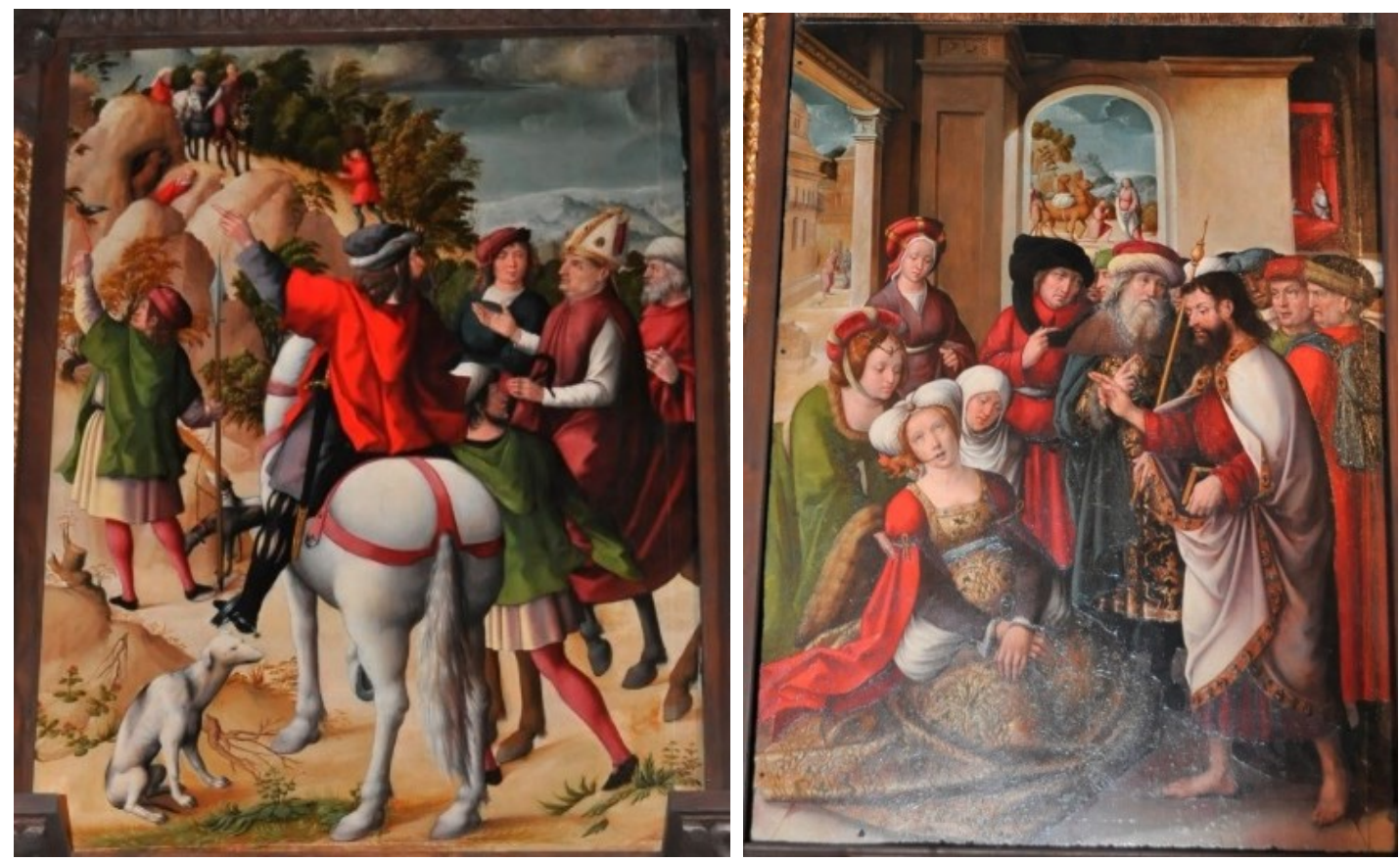

Fig. 3. Alonso Gallego (atrib.), El sacerdote encuentra a San Bartolomé y San Bartolomé exorcisa a la hija del rey, 1515, Retablo de San Bartolomé, Iglesia de San Lesmes, Burgos (C foto autor)

bían reensamblado recientemente, las partes podían formar parte de un mismo conjunto. Además, la iconografía de las pinturas y el relieve le llevará a relacionarlo con el retablo contratado por Picardo y Bigarny. Así, las tallas del retablo incluían a un donante protegido por San Francisco, al que seguía San Esteban. El donante podía tratarse de Francisco Gumiel, comitente del retablo, y la figura de San Esteban haría referencia a la iglesia para la que originariamente se había contratado el retablo.

El siguiente paso sería intentar demostrar documentalmente la tesis. Para ello se apoyan los autores en un dato que aporta Antonio Ponz, que mencionaba el retablo relacionado con Santa Catalina, es decir, el que había pertenecido a la cofradía de Santa Catalina. Efectivamente, al cruzar la documentación de dicha cofradía conservada en San Lesmes con la de los libros de fábrica de la iglesia de San Esteban, se registra la venta del retablo

hallazgo de las tablas de San Lesmes por Damián Luengo. Esto es debido a que, en el siglo XVIII, el retablo se había trasladado de la iglesia de San Esteban a la de San Lesmes.

${ }^{9}$ En principio, el retablo se había desmontado a comienzos del siglo XX. Posteriormente, en 1979, se había vuelto a reutilizar la mazonería para encajar las tablas de pintura, recientemente restauradas, sin sospechar que se trataba de elementos de un mismo conjunto. Para las vicisitudes del retablo dentro de la iglesia de San Lesmes: César Alonso De Porres Fernández, "Identificación de un retablo de Bigarny y Picardo que se daba por desaparecido", Boletín de la Institución Fernán González, 211, (1995), pp. 363374. 
de San Bartolomé en 1705 por 13.600 maravedís. Otro elemento para identificar el retablo de San Lesmes con el contratado por León Picardo y Bigarny para la iglesia de San Esteban será el análisis comparativo de las tallas del retablo con otras obras del escultor borgoñón, llegando a la conclusión de que su estilo es coherente con el taller de Bigarny.

Con estos argumentos, establecen el nuevo o verdadero estilo de León Picardo en base a este retablo de San Bartolomé de la iglesia de San Lesmes. Los autores verán concomitancias con obras de la escuela de Brujas, concretamente obras de Gerard David como El Juicio de Cambises (1498, Musée Communal, Brujas).

Finalmente, en la búsqueda de obras que se puedan atribuir a un pintor de la importancia de Picardo, el artículo centra su atención en distintas pinturas conservadas en España que se puedan atribuir al pintor francés. En este caso, incluirán en su catálogo las pinturas de un artista denominado convencionalmente por Chandler Post como el Maestro de Belorado. Más importante e interesante es la atribución a Picardo de alguna pintura anteriormente catalogada como del Maestro de Támara, actualmente identificado por las investigaciones de José Gabriel Moya Valgañón con Alonso Gallego, pintor originario de Medina del Campo pero que centra su actividad en la primera mitad del siglo XVI en La Rioja ${ }^{10}$. La estrecha relación entre las tablas de San Lesmes y la obra del Maestro de Támara-Alonso Gallego lleva a los autores a proponer una posible identificación de León Picardo con el hasta entonces anónimo autor de Támara, pero ciertas diferencias les hacen ser prudentes en esta consideración, manteniendo la división del catálogo de ambos autores.

Aceptar la tesis de Pilar Silva y Damián Luengo, supone la revisión del catálogo de obras hasta ahora atribuidas a León Picardo, ya que el estilo de las tablas de San Vicente no tiene nada que ver con las de San Lesmes. Para los autores, la calidad de las pinturas de San Lesmes encajaría mejor en la producción de un pintor que adquirió gran fama en el siglo XVI, lo cual utilizan como argumento a favor de su tesis. Supone, por tanto, eliminar del catálogo de obras del francés las tablas con la historia de San Vicente realizadas para Santa Casilda, pero también documentadas en un contrato firmado por Picardo. Este problema lo solucionan argumentando un posible traspaso de las obras de Santa Casilda a un colaborador.

No obstante, si analizamos publicaciones sobre la obra de León Picardo posteriores al artículo, observamos cómo se produce lo que podríamos llamar una postura conciliadora ante el problema de identificar el verdadero estilo del pintor francés. Elisa Bermejo se hace eco de las investigaciones de Pilar Silva y Damián Luengo, aceptando la identificación del retablo de San Lesmes con el contratado por León Picardo, pero sin descartar de su catálogo de obras

10 José Gabriel Moya Valgañón, Alonso Gallego y Andrés de Melgar, pintores, (Logroño: Instituto de Estudios Riojanos, 2013). 
las pinturas hasta ahora atribuidas a partir del retablo de San Vicente. De hecho, utiliza ambos estilos como base para identificar y catalogar las obras de León Picardo en el retablo de la Magdalena de la catedral de Santo Domingo de la Calzada ${ }^{11}$. Asimismo, una visita a la página web del Museo Nacional del Prado nos permite apreciar cómo se produce el mismo hecho conciliador $^{12}$. Sin embargo, Alberto Cayetano Ibáñez Pérez y René Jesús Payo Hernanz sí se harán eco del problema que supone identificar al León Picardo de San Vicente con el de San Lesmes ${ }^{13}$. Para ellos resulta difícil relacionar el estilo de las pinturas de San Lesmes con el de las tradicionalmente señaladas como de León Picardo.

El presente trabajo también pretende, por tanto, aportar una visión alternativa al artículo de Damián Luengo y Pilar Silva, que pueda arrojar algo de luz al problema que se plantea tras su publicación con la figura de León Picardo. Sobre todo, cuando, como hemos visto, la historiografía posterior no ha querido descartar ninguna de las dos posibilidades abiertas en la atribución de obras al catálogo del pintor.

Ciertamente, a tenor de las bien fundamentadas investigaciones y de la documentación encontrada por los autores, no cabe duda de que debemos considerar el retablo de San Lesmes como el contratado por León Picardo y Felipe Bigarny. Pero creo que no podemos afirmar, con la rotundidad que expone el artículo, que hayamos encontrado el "verdadero estilo" de León Picardo. También hay argumentos suficientes para seguir manteniendo las tablas de Santa Casilda como fruto de los pinceles del francés, sobre todo, pensando en la coherencia y fiabilidad que aporta a la hora de atribuirle otras pinturas no documentadas de forma directa. Así, en la catedral de Santo Domingo de la Calzada nos encontramos con un retablo en la capilla de la Magdalena atribuido a Picardo por sus concomitancias estilísticas con las pinturas de la historia de San Vicente. Realmente, no tenemos un documento escrito que certifique de forma directa la autoría de Picardo. Sin embargo, si combinamos las apreciaciones estilísticas con los datos biográficos y los relativos a la fundación y patronazgo de la capilla donde se ubica el retablo, la tesis de la autoría del francés se refuerza. Así, sabemos que Picardo trabajó en el templo calceatense, y además sabemos que la capilla de la Magdalena perteneció a un importante personaje vinculado con Burgos: D. Pedro Carranza, protonotario de la Santa Sede y Maestrescuela de la catedral de Burgos $^{14}$. Lo normal es que de la decoración de su capilla se ocupara un pintor del prestigio en la zona burgalesa como León Picardo ${ }^{15}$.

\footnotetext{
${ }^{11}$ Elisa Bermejo, "León Picardo", en Francisco Fernández Pardo (coord.), Las tablas flamencas en la ruta Jacobea, Catálogo de la exposición (Madrid Fundación BSCH, 27 de septiembre- 7 de noviembre de 1999), (Logroño: Diócesis de Calahorra y La Calzada, 1999), pp. 307-312.

12 Juan Ramón Sánchez del Peral y López, "León Picardo", Enciclopedia del Museo Nacional del Prado, 5, pp. 1732-1733 (En web, https://www.museodelprado.es/enciclopedia/enciclopedia-on-line/voz/picardoleon/, consultada: 27 de noviembre de 2017).

13 Alberto Cayetano Ibáñez Pérez y René Jesús Payo Hernanz, Del Gótico al Renacimiento. Artistas burgaleses entre 1450 y 1600, (Burgos: Cajacírculo, 2008), pp. 192-194.

${ }^{14}$ Saénz Terreros, "Pintura y pintores...", p. 387.

15 Sobre la relación de Léon Picardo y la catedral calceatense, Ibidem, pp. 389-391.
} 
Pero centrándome en las tesis expuestas en el artículo de Damián Luengo y Pilar Silva, también se puede establecer una antítesis. En primer lugar, el argumento de la mediocre calidad de las obras hasta ese momento atribuidas a León Picardo, impropias de un pintor de su fama, había sido resuelto ya por Diego Angulo al publicar su artículo sobre León Picardo de 1945. Para Angulo, a veces la fama de los pintores tiene más que ver con sus dotes intelectuales que con las propiamente artísticas, citando los ejemplos de Francisco Pacheco (1564-1644) y Pablo de Céspedes (1540-1608). Este era el caso de Picardo según las obras conocidas hasta entonces. Pero la aparición en el mercado madrileño de una serie de tablas (entre ellas, la Purificación que adquirirá el Museo Nacional del Prado) le hacen cambiar de opinión y "concederle un puesto de primer orden en la pintura burgalesa del Renacimiento"16. Hay que añadir que una comparación de las tablas del León Picardo de Santa Casilda con autores contemporáneos como Bartolomé de Castro (activo en Castilla en el primer tercio del siglo XVI), u otro importante autor burgalés como Alonso de Sedano (activo en Castilla desde finales del siglo XV hasta el primer tercio del siglo XVI), serviría también para hacernos una idea de que estamos ante un autor de calidad superior a la media de la pintura española de la época. Suficientemente elocuentes son, por ejemplo, la Purificación del Museo del Prado o el San Jerónimo de la capilla de la Magdalena en la catedral de Santo Domingo de la Calzada.

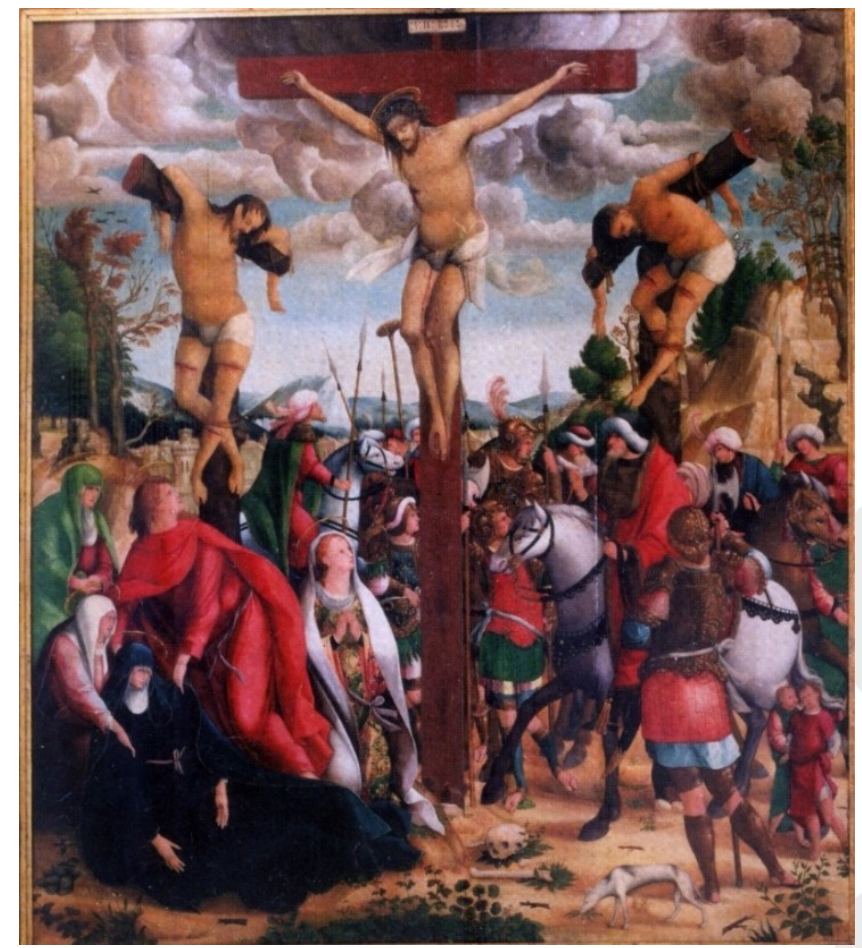

Fig. 4. Alonso Gallego, Calvario, Museo de La Rioja, Logroño ${ }^{17}$

${ }^{16}$ Angulo Iñiguez, "León Picardo...", p. 84.

17 Imagen tomada de José Gabriel Moya Valgañón, Alonso Gallego..., lám. 21, p. 33. 
En segundo lugar, la explicación de que la ejecución de las pinturas para el retablo de Santa Casilda, contratado por Picardo, pudo ser traspasada a un colaborador es perfectamente plausible. Pero también se podría aplicar al caso de las tablas de San Lesmes, como reconocen los propios autores. Se apoyan entonces en una mayor importancia del encargo de Francisco Gumiel sobre el de Santa Casilda, dato con el que no están de acuerdo algunos investigadores ${ }^{18}$.

Sí es más convincente la relación con el Maestro de Támara (Alonso Gallego), vinculación ya establecida por Diego Angulo en 1954 al citar de forma tangencial las tablas de San Lesmes ${ }^{19}$. Pero precisamente esta relación puede interpretarse de otra forma, y considerar las tablas de San Lesmes como obras ejecutadas no por Picardo, sino por Alonso Gallego. Es esta una cuestión que desarrollaré más adelante.

Desde luego, hay que considerar que alguna de las dos obras documentadas (Santa Casilda o San Lesmes) fue hecha por otro autor distinto a Picardo. La controversia creada por la documentación, que nos presenta dos obras de estilo diferente contratadas por un mismo artista, podría explicarse a la luz de la lectura e interpretación de las capitulaciones. En este sentido, René Payo aporta una apreciación sobre el retablo de San Lesmes: tal vez León Picardo se encargó de la policromía del retablo, dejando la pintura para otro autor ${ }^{20}$. El comentario es muy oportuno, y la propia lectura de los contratos de San Lesmes y de Santa Casilda podría dar pie a esta interpretación. En ambos se obliga a León Picardo a realizar la pintura de los retablos. Pero el término "pintura" ciertamente puede hacer referencia a la policromía del retablo, y no a la ejecución de las historias. La utilización de la palabra "pintura" para la policromía de los retablos era común en la época, así como la de "pincel" para la pintura de historias o figuras ${ }^{21}$. La diferencia que se hace en ambos contratos entre "pintura" y "de pincel" o "pincelar" puede corroborar esta teoría. Además, tal vez el "ha de aver" utilizado para referirse a las historias no vincule a Picardo en la ejecución.

No sería la primera vez que se interpreta de manera errónea la documentación al hablar de la pintura de un retablo. Así lo vemos en el caso del retablo de Carbonero el Mayor (Segovia). Sus pinturas están actualmente atribuidas a la labor de algún flamenco en la órbita de Ambrosius Benson,

\footnotetext{
18 "Sin embargo, esta explicación tiene algunos problemas, ya que el retablo de los Gumiel -la mejor de sus creaciones conocidas- no se trata de un encargo de gran importancia, siendo a nuestro juicio de mayor trascendencia otras de sus producciones que, sin embargo, son más deficientes en sus formas". Ibáñez Pérez et al., Del Gótico al Renacimiento..., p. 193.

${ }_{19}$ Angulo Iñiguez, Ars Hispaniae..., p. 106. Diego Angulo no se atrevió tampoco a unificar la producción del entonces Maestro de Támara con el autor de las tablas de San Lesmes, al que veía como "más flamenco".

${ }^{20}$ Ibáñez Pérez et al., Del Gótico al Renacimiento..., p. 193.

${ }^{21}$ En el mismo contrato para Santa Casilda parece hacerse esta distinción. Así, para el retablo de San Vicente se habla de hacer "de madera y pintura", mientras que en una cláusula posterior se habla de "pincelar toda la dha capilla". Silva Maroto, "Pintura española...", p. 175. Otro ejemplo lo tenemos en el testamento de Isabel la Católica, donde también se utiliza el término "pincel" para referirse a un retablo de pintura: "un retablo de pincel (...) que está hecho de tres piezas (...)", Francisco Javier Sánchez Cantón, Libros, tapices y cuadros que coleccionó Isabel la Católica, (Madrid: CSIC, 1950), p 57.
} 
pero, en su momento, se relacionaron con un pintor español, Diego de Rosales, debido a que se le habían hecho distintos pagos por la pintura del mismo. Sin embargo, el descubrimiento posterior del retablo de las Flores de Ávila como obra contratada por Rosales descartó finalmente su intervención, ya que nos revela un artista influenciado por la obra de Alonso Berruguete. Se acepta así, actualmente, que las referencias documentales a Rosales se refieren a su intervención en la policromía del retablo ${ }^{22}$, siendo las tablas pictóricas fruto de la importación desde Flandes.

Hay que añadir que León Picardo realizará el dorado y policromía de multitud de retablos, sobre todo en colaboración con Felipe Bigarny, y que adquirió gran fama en su época en esas labores. Precisamente, esa es una diferencia entre los contratos de San Lesmes y Santa Casilda: mientras que en el primero lo firma al lado de Bigarny, en el dedicado a San Vicente se compromete él solo, por lo que podría ser un argumento a favor de la intervención de Picardo en la ejecución de las pinturas. Es habitual encontrar a Picardo trabajando en la policromía, dorado y estofado de los retablos que contrataban de manera mancomunada con Bigarny. Por ejemplo, ambos contratan en septiembre de 1529 el retablo "de talla y pintura y dorado y estofado" para la colegiata burgalesa de Valpuesta ${ }^{23}$. Tal vez tengamos en San Lesmes otro ejemplo de tantos retablos contratados por ambos artistas, en el que Bigarny se encarga de la obra de talla, y Picardo de su policromía. Las desavenencias habituales por el resultado final de la obra pueden aportar pistas sobre asunto. El mayordomo de San Esteban nombra a Francisco de Colonia y a Alonso de Sedano como jueces de la obra, y las referencias que se hacen a Picardo tienen que ver con la policromía, sin ninguna mención a las pinturas ${ }^{24}$.

\footnotetext{
22 Para este retablo, Fernando Collar de Cáceres, "Informe histórico artístico", en VV. AA, Retablo de Carbonero el Mayor: restauración e investigación, Madrid, Instituto del Patrimonio Histórico Español, 2003, pp. 11-89. Collar de Cáceres relaciona las pinturas con el pintor lombardo afincado en Brujas Ambrosius Benson, que tuvo una gran producción dedicada a la exportación, sobre todo a España. De ahí que en su momento se le denominara con el nombre convencional de "Maestro de Segovia". Sin embargo, el profesor Didier Martens considera que las pinturas son obra de una mano distinta de la de Benson, aunque también dentro de su influencia, atribuyéndolas a un todavía anónimo pintor al que denomina "Maestro de Carbonero el Mayor". Didier Martens, Peinture flamande et goût Ibérique, (Bruxelles: Le Livre Timperman, 2010), pp. 161-171.

23 "(...) yo don Pero Xuarez de Figueroa y de Velasco, dean de la santa iglesia desta muy noble çibdad de Burgos e arcediano de Valpuesta (...) y conozco y digo que por quanto ay necesidad de hazer un rretablo en la dicha iglesia de Balpuesta por ende que yo me convengo e ygualo con vos maestre Felipe Bigarni escultor y Lean Picardo pintor vecinos de la dicha çibdad de Burgos para que ayays de hazer y hagays el dicho rretablo para la dicha yglesia de talla y pintura y dorado y estofado en esta manera que le ayays de hazer y le agays de la manera y conforme a la traça y muestra que queda en mi poder firmada del escriuano de yuso contenido el qual dicho rretablo aveys de dar hecho y acabado conforme a la dicha traça de talla e pintura e dorado y estofado y hecho y acabado y puesto y asentado en la dicha mi iglesia de Valpuesta". Isabel Fuentes Rebollo, "Bigarny, Picardo y el retablo de la colegiata de Valpuesta (Burgos)", Boletín del Museo Nacional de Escultura, 4, (2008), p. 7.

24 "yo Francisco de Colonia e Alonso de Sedano juntos (...) fallamos que que debemos mandar e mandamos que maestre felipe ponga ciertas columbetas en la caxa de Sant bartolomé segund que pertenece a la dicha obra e asimismo ponga en el guarda polvo su uasamiento de romano e sus remates de romano conforme a la dicha obra que está fecha $\mathrm{E}$ asimismo mandamos a león picardo que la dore e pinte conforme a la obra de dicho Retablo (...) den e paguen a maestre felipe por la imagenería e talla e madera 55.000 maravedís... e den e paguen... a león picardo por la pintura e dorar 45.000". López Mata, barrio y la iglesia..., pp. 107-108.
} 
Tampoco sería una cuestión extraña la inclusión de una pintura ajena en un retablo contratado por ambos. Así, un ejemplo lo tenemos en la capilla de Santa Ana de la iglesia de Santa María del Castillo en Cervera de Pisuerga. El retablo fue contratado por León Picardo y Felipe Bigarny, y posteriormente se añadirá una adoración de los magos, atribuida a Juan de Flandes ${ }^{25}$.

$\mathrm{Si}$, como en mi caso, nos decantamos por seguir considerando las tablas de Santa Casilda como las genuinas de Picardo, la cuestión sería entonces buscar un origen o autor para estas tablas de San Lesmes. Proponemos también diversas alternativas. Una de ellas puede ser una posible importación de las pinturas para ensamblarlas en el retablo. Las palabras que Diego Angulo dedica a las pinturas de San Lesmes, al equipararlas en su estilo al del Maestro de Támara (Alonso Gallego), me hicieron pensar en esta opción. Angulo habla de las pinturas como "más flamencas", por lo que se podía pensar en una posible procedencia foránea. Esto no era una cuestión extraña en Castilla, con un dinámico comercio con los Países Bajos, y sobre todo con Brujas, durante los siglos XV y XVI a través de los puertos del Cantábrico. Un claro ejemplo es el citado retablo de la iglesia parroquial de Carbonero el Mayor.

Sin embargo, esta posible vía de importación se puede resolver mediante un simple análisis material de las tablas de San Lesmes. Aunque no he podido comprobar si están realizadas sobre roble, típico en las tablas flamencas, sí he podido medir el grosor de las tablas inferiores. Sabemos que en España se trabaja con un espesor mayor que en Flandes, cuyas tablas no suelen sobrepasar el centímetro ${ }^{26}$. En el caso de San Lesmes, el grosor es de aproximadamente 1,5 centímetros, lo cual encaja más con el tipo de soporte utilizado en España.

Hay además otra cuestión que sirve de apoyo para descartar esta procedencia flamenca, y es una cuestión referida a la indumentaria, a la que apuntan Damián Luengo y Pilar Silva27. Así, a pesar de la influencia de la moda nórdica, en una de las figuras femeninas del retablo de San Lesmes observamos un trenzado típico de España, que observo también en uno de los relieves del retablo de la capilla de Santa Ana de Cervera de Pisuerga.

Esto me lleva a pensar en un traspaso o cesión de las historias de San Bartolomé a un pintor de confianza. $Y$ para ponerle nombre a este pintor cesionario de las pinturas, es importante retomar la intuición de Diego Angulo, aceptada por Damián Luengo y Pilar Silva, sobre su relación con el Maestro de Támara. De esta forma, se podría identificar a Alonso Gallego como el autor de las tablas de San Lesmes. Desde luego, la estrecha relación de las pinturas de San Lesmes con las de Alonso Gallego, algunas de las

\footnotetext{
${ }^{25}$ Huidobro Serna, "Artistas burgaleses...", pp. 190 y 191.

${ }^{26}$ Fernández Pardo, "Tablas flamencas...", pp. 124 y 125.

27 Luengo Pedrera et al., "Identificación...", p. 36.
} 
cuales no están lejos en calidad de las tablas de la historia de San Bartolomé, pueden hacer plausible esta teoría.

La cesión o traspaso de obras entre artistas era una costumbre más habitual de lo que podemos suponer. Pero para el caso que nos ocupa, he de citar un caso muy interesante no ya de traspaso de obra, sino de subcontratación. Se trata del acuerdo entre el pintor afincado en Llerena, Estacio de Bruselas, y el sevillano Luis de Vargas, por el que este último se compromete a realizar la pintura de diez historias. Lo interesante del asunto es que se estipula que sea el propio Estacio el que facilite a Luis de Vargas los tableros, ya aparejados y cortados con unas medidas muy concretas ${ }^{28}$. El pintor sevillano debía devolverlos, en el plazo de cinco meses, pintados con las historias que Estacio le indicara. Esto lleva a pensar que Estacio había concertado un retablo para el que no sería artífice de las pinturas, sino que se limitaría a subcontratarlas a otro pintor, en este caso Luis de Vargas ${ }^{29}$. Y este pudo ser el caso del retablo de San Lesmes: Picardo y Bigarny se ocuparían de la labor de talla y policromado, encargando la labor de las historias de pincel a un pintor de su confianza como Alonso Gallego.

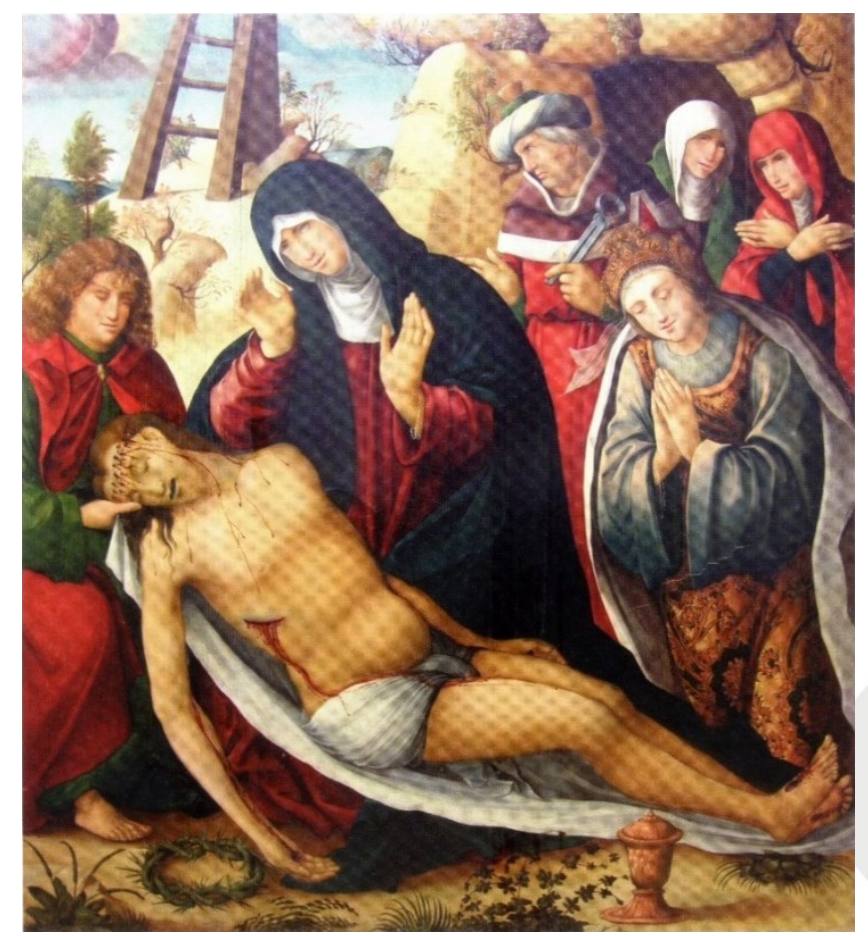

Fig. 5. Alonso Gallego, Quinta Angustia, Colección particular, Logroño ${ }^{30}$

\footnotetext{
${ }^{28}$ Para todos los datos relativos a este concierto, y la consulta de la transcripción del contrato, Antonio Joaquín Santos Márquez, "Testimonio del vínculo entre dos pintores: Luis de Vargas y Estacio de Bruselas", Norba-Arte, XXVI, (2006), pp. 245-249.

${ }^{29}$ Los motivos de la elección de un pintor alternativo pueden ser por considerarlo de mayor calidad o modernidad en su estilo, ajustándose a los gustos del comitente del retablo.

${ }^{30}$ Imagen tomada de José Gabriel, Moya Valgañon, Alonso Gallego..., lám. 92, p. 98.
} 
Alonso Gallego es un pintor, además, relacionado con León Picardo, y sabemos por las investigaciones de José Gabriel Moya que el francés le pudo ceder la ejecución de algunas obras contratadas ${ }^{31}$. Pintor originario de Medina del Campo, se trasladó a trabajar a tierras riojanas, donde será un pintor apreciado $^{32}$. En 1497 era ya vecino de Nájera, donde presenta ante el concejo una carta ejecutoria de hidalguía, que será aceptada el 18 de diciembre. Allí establece vínculos con León Picardo, ya que ambos trabajaron para la catedral de Santo Domingo de la Calzada.

Las concomitancias de estilo entre las pinturas de San Lesmes y Alonso Gallego son evidentes: las fisonomías, el gusto por las figuras masculinas tocadas con turbantes, el tipo de paisaje y vegetación, los tipos de solados, la utilización de arquitecturas renacientes en el interior, o incluso detalles más concretos como la representación del perro en tablas como el Calvario del Museo de la Rioja (fig 4), coincidente con el que podemos observar en la tabla El Sacerdote encuentra a San Bartolomé de San Lesmes (fig. 3). Aún así, las reservas de Diego Angulo a la hora de adjudicar las tablas de San Lesmes al Maestro de Támara (Alonso Gallego) están más que justificadas. La mayor delicadeza de estas pequeñas tablas son las que le deben llevar a verlas como "más flamencas"33. Pero si nos detenemos en algunas de las tablas salidas de los pinceles de Alonso Gallego, observamos detalles de calidad que no desmerecen las pinturas de San Lesmes. Una de estas obras destacadas es la Quinta Angustia conservada en una colección particular de Logroño (fig. 5) ${ }^{34}$. Estas notas más refinadas en relación con las tablas de San Lesmes que vemos en las mejores pinturas de Alonso Gallego, son las que llevan a Damián Luengo y Pilar Silva a restituir alguna de sus obras a la labor de León Picardo, como es el caso del Bautismo de San Agustín (Museo Municipal de Villadiego, Burgos). Creo, por tanto, que podemos dar un paso más en la acertada apreciación de Diego Angulo, y resolver sus reservas a la hora de identificar al Maestro de Támara, esto es, Alonso Gallego, con el autor de las pinturas de San Lesmes ${ }^{35}$.

\footnotetext{
31 José Gabriel Moya Valgañón comenta una posible cesión de las pinturas de los respaldos y retablos del coro de la catedral calceatense, inicialmente contratados por León Picardo. "(...) este trascoro de Santo Domingo de la Calzada (...) probablemente se concertará inicialmente con León Picardo, del que éstos [Alonso Gallego y Andrés de Melgar] actuarían como cesionarios". Moya Valgañón, Alonso Gallego..., p. 13. "Con León Picardo debió tener amistad más duradera y han debido influenciarse mutuamente. Como cesionario suyo realizó obras de dorado y policromía en la obra del trascoro calceatense y, sospecho, que, en alianza con él, estaría obligado a pintar las tablas de sus retablos (...) al ocuparse el francés de trabajos más provechosos en Oviedo". Ibidem, p. 110.

32 "(...) no cabe duda que a él se recurrió con mayor frecuencia que a ningún otro, al menos en lo que se refiere a pinturas en tabla. Entre sus clientes figurarían las dos abadías más importantes de la comarca, San Millán de la Cogolla y Santa María la Real de Nájera. Estuvo al servicio del duque don Pedro Manrique (...). Pero también obtendría trabajos para otras ramas de los Manrique de Lara". Ibidem, p. 108.

${ }_{33}$ Tal vez el menor tamaño de las tablas de San Lesmes permita al pintor recrearse más en el refinamiento de las pinturas, o simplemente hay que observar una intervención exclusiva del autor, con menos participación del taller.

${ }_{34}$ Ibidem, p. 97.

35 Damián Luengo y Pilar Silva mantienen la precaución a la hora de identificar la totalidad de las obras del hasta ese momento denominado Maestro de Támara, con el autor de las pinturas de San Lesmes. Para ellos, o bien se trata de dos autores distintos (León Picardo en las pinturas de San Lesmes y similares, y el Maestro de Támara en obras en las que se aprecia un estilo más evolucionado y expresivo, como el Calvario de la Diputación de Logroño), o de un mismo pintor, esto es, León Picardo, en fases diferentes. Luengo Pedrera et al., "Identificación...", pp. 41-43.
} 
Como conclusión, aunque no hay duda de que el retablo de la iglesia de San Lesmes se corresponde con el contratado por Bigarny y León Picardo originalmente para la iglesia de San Esteban, creo que no se puede afirmar con rotundidad que las pinturas fueran ejecutadas finalmente por el pintor francés. Sin descartar su intervención, debemos mantener cautela a la hora de desechar de su mano las pinturas contratadas para la iglesia de Santa Casilda, y el catálogo posterior formado a partir de ellas. En mi opinión, hay también argumentos suficientes para pensar que, finalmente, León Picardo traspasó la ejecución de las tablas con la historia de San Bartolomé a un pintor de su confianza como Alonso Gallego.

Hasta que aparezcan nuevos documentos o investigaciones posteriores que puedan aportar luz al asunto y dirimir esta controversia, debemos mantener la prudencia respecto a este "verdadero estilo" de León Picardo, aunque sin descartar que, efectivamente, las tablas de San Lesmes hayan salido de sus pinceles. 
Bibliografía

Angulo Iñiguez 1945: Diego Angulo Iñiguez, "León Picardo", Archivo Español de Arte, 68, (1945), pp. 84-96.

Angulo Iñiguez 1954: Diego Angulo Iñiguez, Ars Hispaniae, v. XII, Pintura del Renacimiento, (Madrid: ed. Plus-Ultra, 1954).

Angulo Iñiguez 1964: Diego Angulo Iñiguez "El retablo de Santa Catalina de León Picardo, en Barbarín", Príncipe de Viana, 94 y 95, (1964), pp. 49-50.

Fernández Somoza 1997: Gloria Fernández Somoza, "El mundo laboral del pintor del siglo XV en Aragón", Locus Amoenus, 3, (1997), pp. 39-49.

Fuentes Rebollo 2001: Isabel Fuentes Rebollo, "Felipe Bigarny veedor y examinador de obras de talla", Boletín del Museo Nacional de Escultura, 5, (2001), pp. 7-10.

Fuentes Rebollo 2008: Isabel Fuentes Rebollo, "Bigarny, Picardo y el retablo de la colegiata de Valpuesta (Burgos)", Boletín del Museo Nacional de Escultura, 4, (2008), pp. 7-14.

Huidobro Serna 1939: Luciano Huidobro Serna, "Artistas burgaleses. León Picardo pintor y escultor", Boletín de la Comisión de Monumentos Históricos y Artísticos de Burgos, 66, (1939), pp. 189-194.

Ibáñez Pérez y Payo Hernanz 2008: Alberto Cayetano Ibáñez Pérez y René Jesús Payo Hernanz, Del Gótico al Renacimiento. Artistas burgaleses entre 1450 y 1600, (Burgos: Cajacírculo, 2008).

López Mata 1946: Teófilo López Mata, El barrio y la iglesia de San Esteban de Burgos, (Burgos: Publicaciones del Excelentísimo Ayuntamiento de Burgos, 1946).

Luengo Pedrera y Silva Maroto 1996: Damián Luengo Pedrera y Pilar Silva Maroto, "Identificación del verdadero estilo de León Picardo", Archivo Español de Arte, 273, 99, (1996), pp. 23-44.

Madrid 1999: Las tablas flamencas en la ruta Jacobea, Catálogo de la exposición (Madrid Fundación BSCH, 27 de septiembre- 7 de noviembre de 1999), (Logroño: Diócesis de Calahorra y La Calzada, 1999).

Martens 2010: Didier Martens, Peinture flamande et goût Ibérique, (Bruxelles: Le Livre Timperman, 2010).

Martínez Burgos 1951: Matías Martínez Burgos, "Datos familiares de León Picardo pintor", Boletín de la Institución Fernán González, 115, 19, (1951), pp. 490-499. 
Miguel Diego 1987: Teresa de Miguel Diego, Documentos para la historia del arte en la provincia de Salamanca. Siglo XVI, (Salamanca: Ediciones de la Diputación de Salamanca, 1987).

Moya Valgañón 2013: José Gabriel Moya Valgañón, Alonso Gallego y Andrés de Melgar, pintores, (Logroño: Instituto de Estudios Riojanos, 2013).

Porres Fernández 1995: César Alonso de Porres Fernández, "Identificación de un retablo de Bigarny y Picardo que se daba por desaparecido", Boletín de la Institución Fernán González, 211, (1995), pp. 363-374.

Rathfon Post 1947: Chandler Rathfon Post, A History of Spanish Painting, tomo IX, (Cambridge: Harvard University Press, 1947).

Sáez Terreros 1981: María Victoria Sáez Terreros, "Pintura y pintores de la primera mitad del siglo XVI en Santo Domingo de la Calzada", Boletín de la Institución Fernán González, 197, (1981), pp. 377-416.

Sánchez Cantón 1950: Javier Sánchez Cantón, Libros, tapices y cuadros que coleccionó Isabel la Católica, (Madrid: CSIC, 1950).

Santos Márquez 2006: Antonio Joaquín Santos Márquez, "Testimonio del vínculo entre dos pintores: Luis de Vargas y Estacio de Bruselas", Norba-Arte, XXVI, (2006), pp. 245-249.

Silva Maroto 1994: Pilar Silva Maroto, "La pintura española sobre tabla de los siglos XV y XVI, en la Catedral de Burgos", en Las pinturas sobre tabla de los siglos XV y XVI en la Catedral de Burgos, (Burgos: Cabildo Metropolitano y Asociación de Amigos de la Catedral, 1994).

VV. AA. 2003: VV. AA., Retablo de Carbonero el Mayor: restauración e investigación, Madrid, Instituto del Patrimonio Histórico Español, 2003.

Yarza Luaces 1994: Joaquín Yarza Luaces, "Posible respuesta a una duda: el maestro desconocido del retablo gótico de Ejea de los Caballeros y el artista empresario", en Tiempo y espacio en el arte. Homenaje al profesor Antonio Bonet Correa, vol. I, (Madrid: Editorial Complutense, 1994), pp. 149-160.

Recibido: $11 / 09 / 2017$

Aceptado: $30 / 10 / 2017$ 